\title{
Potentially pathogenic bacteria isolated from neglected air and surfaces in hospitals
}

\author{
Mayk Teles de Oliveira ${ }^{1}$, Lorranny Mayara Silva Cunha ${ }^{1}$, \\ Fernanda Cardoso Cruz ${ }^{1}$, Nathany Kelly Ribeiro Batista ${ }^{1}$, Eric de Souza Gil ${ }^{3}$, \\ Virgínia Farias Alves', Maria Teresa Freitas Bara ${ }^{2}$, Ieda Maria Sapateiro Torres ${ }^{\left({ }^{*}\right.}$ \\ ${ }^{1}$ Research Laboratory of Medicines and Food Microbiology, Faculty of Pharmacy, Federal University \\ of Goiás, Goiânia, Goiás, Brazil, ${ }^{2}$ Research Laboratory of Natural Products, Faculty of Pharmacy, \\ Federal University of Goiás, Goiânia, Goiás, Brazil, ${ }^{3}$ Research Laboratory of Pharmaceutical and \\ Environmental Analysis, Faculty of Pharmacy, Federal University of Goiás, Goiânia, Goiás, Brazil
}

\begin{abstract}
Hospital infections (HI) are a serious public health problem in many countries. Several studies have identified strains correlating to surgical site infections, many with multi-resistance. The goals of this study was to quantify, to identify and to verify the resistance profile of microorganisms collected at two hospitals settings, and to alert health professionals how environmental contamination can influence hospital infection rates. For air sampling in operating rooms, intensive care unit and materials sterilization center, the impaction method (Spin Air, IUL $($ ) and passive sedimentation were used. For the isolation of bacteria on surfaces and uniforms contact plates (RODAC®) were used. Identification of the microorganisms was performed using Vitek 2 Systems. The antibiograms were conducted according to the disk diffusion method recommended by CLSI. The surgical center of hospital B presented more than $500 \mathrm{CFU} / \mathrm{m}^{3}$ in aerial microbial load. In the aerial microbiota of the sampled areas of both hospitals, M. luteus, S. haemolyticus and $S$. hominis spp hominis were the prevalent microorganisms, with a percentage greater than $30 \%$. On the surfaces and uniforms there was a prevalence of M. luteus (40\%) and S. hominis spp hominis (20\%) among others, and some of the resistant strains were isolated from environments with microbial load within the recommended limits.
\end{abstract}

Keywords: Drug resistance. Environmental monitoring. Cross infection. Air quality.

\section{INTRODUCTION}

To ensure a satisfactory internal air quality, the hospital environment must be constantly monitored in order to protect patients and workers from acquiring hospital infections and occupational diseases. (Birgand et al., 2015; Cabo Verde et al., 2015; Emuren, Ordinioha, 2016)

The origin of microorganisms responsible for $\mathrm{HI}$ outbreaks may come from humans (Munoz-Price et al., 2012) (e.g.: hands and uniforms), system of climatization (Kumari et al., 1998), inefficient sterilization/cleaning

*Correspondence: I. M. S. Torres. Laboratório de Microbiologia de Medicamentos e Alimentos. Faculdade de Farmácia. Universidade Federal de Goiás, Brasil. Phone: +5562991383940. E-mail: ieda.mst@uol.com.br procedure (Dancer, 2009), infiltration of humidity (Baughman, Arens, 1996) and external microbial load (Prussin, Marr, 2015), and these factors need to be associated with favorable conditions for microbial growth. (Park et al., 2013)

Although some microorganisms found in the air, surfaces and uniforms of hospital environments are not considered pathogenic for healthy people, studies show that they are causing infections in people with compromised immune systems (Litvinov et al., 2015). In addition, hospital microorganisms are likely to be multidrug resistant (Cornejo-Juárez et al., 2015), which makes environmental monitoring an important tool to control and prevent nosocomial infection outbreaks, and reduce the rate of morbidity, mortality and costs. (Galvin et al., 2012; Neidell et al., 2012). 
Many studies have evaluated air quality in hospitals environment (Agodi et al., 2015; Birgand et al., 2015; Cabo Verde et al., 2015; Creamer et al., 2014; Emuren, Ordinioha, 2016; Prussin, Marr, 2015) but in these studies, the resistance profile of isolated microorganisms was not investigated.

The present study aimed to evaluate and determine the resistance profile of microorganisms isolated from air, surfaces and uniforms, commonly neglected places, of different sectors of hospitals.

\section{MATERIAL AND METHODS}

\section{Study design}

A prospective study on airbone, surface and uniforms microbiota was carried out in two small private hospitals (A and B) specialized in ophthalmologic, aesthetic, oncological and orthopedic surgeries, located in urban areas in the city of Goiânia/GO, and in three hospital sites: the operating room theater (ORT); the intensive care unit (ICU); the material and sterilization center (MSC). Three sampling campaigns were performed at each site at Hospital A and Hospital B, for six consecutive weeks.

In all ORTs evaluated there was a ventilation system equipped with $0.3 \mathrm{~mm}$ 99.97\% Hight Efficiency Particulate Air (HEPA) filters. The ORT air pressure was $\geq 5 \mathrm{~Pa}$ higher than in adjacent rooms (only in Hospital A). In all ICUs and MSCs evaluated there was split type air conditioner and there was no high pressure compared to adjacent rooms.

\section{Microbiological air sampling}

Microbiological air counts were measured by impaction using air sampler (SpinAir ${ }^{\circledR}$, IUL S.A., USA) with a flow rate of $100 \mathrm{l} / \mathrm{min}$ (with a sampled volume of $1 \mathrm{~m}^{3}$ ), and the equipment was approximately $1 \mathrm{~m}$ above the floor. All samples were collected during the normal work routine, and especially in the ORT, the collection was initiated after the first incision (one sampling per room for three weeks).

To assess aerobic mesophilic bacterial counts (AMBCs) in indoor air by the impaction method, tryptic soy agar (TSA) (Scharlau ${ }^{\circledR}$, Barcelona, Spain), mannitol salt (MSA) (Kasvi ${ }^{\circledR}$, Curitiba, Brazil) and cetrimide agar (CA) $\left(\mathrm{Kasvi}^{\circledR}\right.$, Curitiba, Brazil) were used in duplicate and the plates were incubated at 20- $25^{\circ} \mathrm{C}$ for two days, followed by incubation at $30-35{ }^{\circ} \mathrm{C}$ for three days, proceeding with the counting of colony forming units (CFU).

For passive sampling only TSA was used and these plates were exposed at predetermined locations for one hour. The incubation procedure was the same as the process that was used in the impaction method.

\section{Surface and uniforms sampling}

Surface and uniforms sampling were performed with the aid of the contact plates (Kasvi ${ }^{\circledR}$, Curitiba, Brazil) containing TSA with $0.1 \%$ lecithin (Scharlau ${ }^{\circledR}$, Barcelona, Spain) and 0.7\% Tween 80 (Dinâmica ${ }^{\circledR}$, São Paulo, Brazil). The contact plates were gently pressed onto the surface or uniforms for 10 seconds (one per surface and uniform). After collecting, the plates were incubated under the same conditions and time as in the previous section.

In the ORT the collection was performed on a wall (closest to the area of action) and in the sterile surgical gown (chest and forearm). In the ICU, the collections were implemented on a wall, sink, bed and worker's uniform (chest). In the MSC, on a wall, autoclave cover and worker's uniform (chest), under aseptic conditions.

\section{Identification of microorganisms}

Isolated bacteria were identified using the biochemical identification cards of the Vitek ${ }^{\circledR} 2$ Systems (BioMérieux, Inc., France).

\section{Antimicrobial susceptibility}

The antimicrobial susceptibility test was performed by disk diffusion for the microorganisms indicated by the Clinical \& Laboratory Standards Institute guidelines. (CLSI, 2015)

Staphylococcus aureus ATCC 25923, Pseudomonas aeruginosa ATCC 27853 and Escherichia coli ATCC 25922 were used as control microorganisms for the disk diffusion tests.

\section{Data analysis}

For the data analysis, the Analysis of Variance (ANOVA) of single factor with significance level $\mathrm{p}<0.01$ using Microsoft Excel ${ }^{\circledR} 2010$ to determine differences between passive and impaction sampling was performed. 


\section{RESULTS}

\section{Microbiological air, surface and uniforms sampling}

The results for the microbial load isolated in the air, surfaces and uniforms of the analyzed hospitals are present in Figures 1 and 2. In all sectors analyzed the microbial load was over $200 \mathrm{CFU} / \mathrm{m}^{3}$. In surfaces and uniforms microbial load indices were greater than $5 \mathrm{CFU} /$ $\mathrm{cm}^{2}$, reaching values of approximately $130 \mathrm{CFU} / 30 \mathrm{~cm}^{2}$ in a sector of Hospital B (Figure 2). As there was no ICU in Hospital B, the collection procedure was performed in the post-surgical rest room (PSRR).

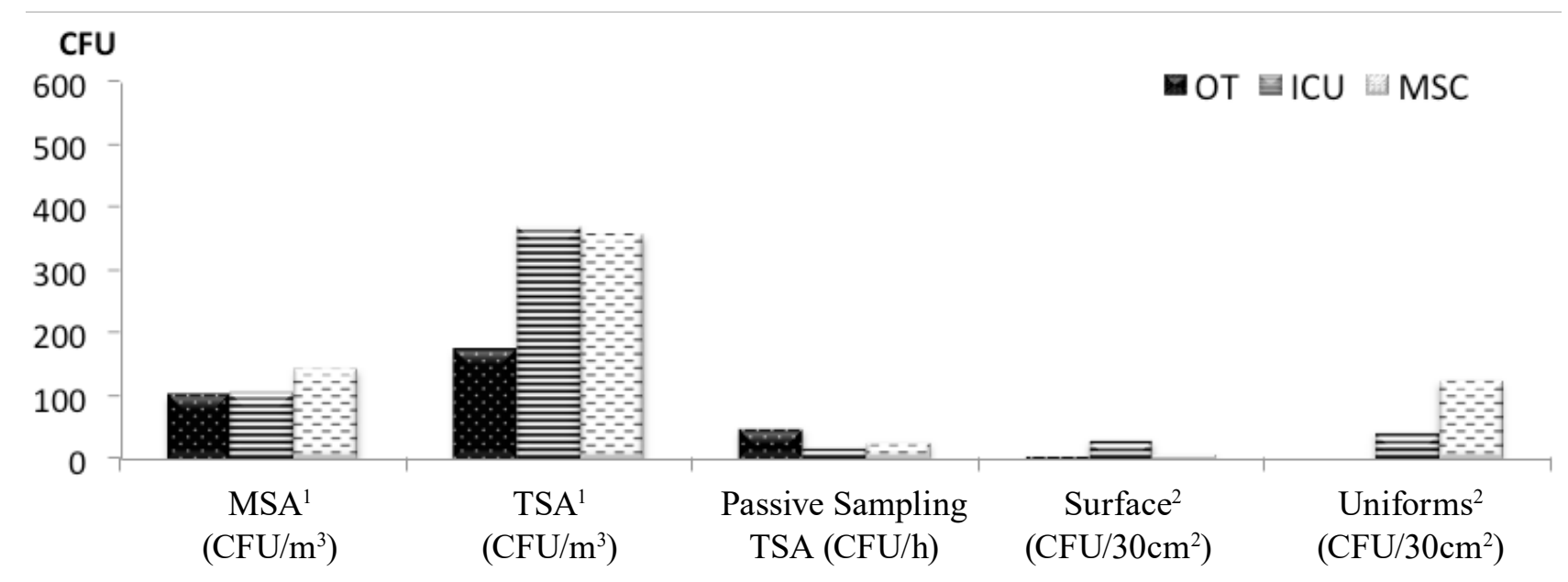

FIGURE 1 - Count of microorganisms isolated from air, surfaces and uniforms of the Hospital A.

OT: operating theater; ICU: intensive care unit; MSC: material and sterilization center; MSA: mannitol salt agar; TSA: tryptic soy agar; 1: active sampling; 2: RODAC plate sampling;

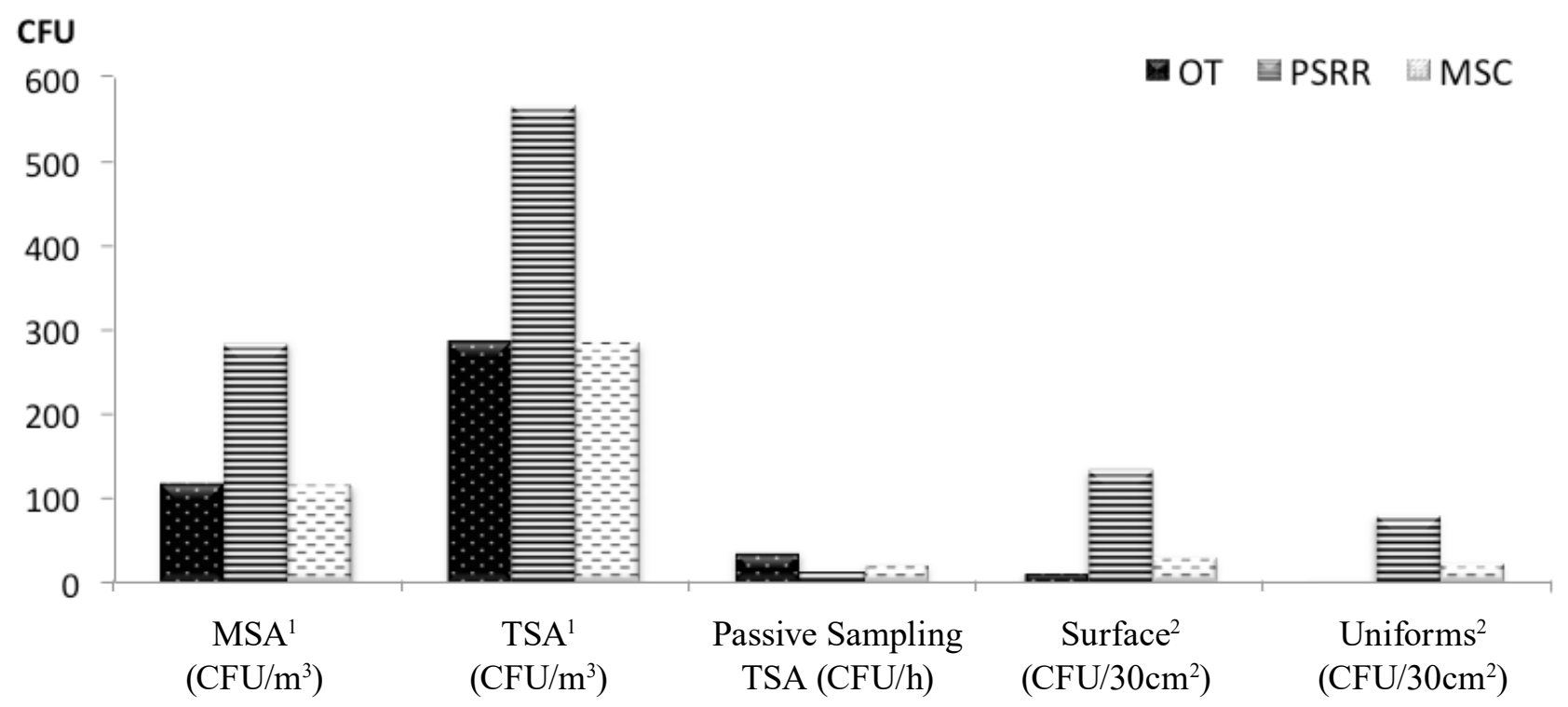

FIGURE 2 - Count of microorganisms isolated from air, surfaces and uniforms of the Hospital B.

OT: operating theater; PSRR: Post-surgical rest room; MSC: material and sterilization center; MSA: mannitol salt agar; TSA: tryptic soy agar; 1: active sampling; 2 : RODAC plate sampling;

In the sampling by impaction in cetrimide agar, a selective medium for $P$. aeruginosa, there was no growth in any evaluated environment.
In this study, a statistical difference $(\mathrm{p}<0.01)$ between the active and passive sampling methods was noticed in all sectors of both hospitals evaluated. 


\section{Identification of microorganisms}

Regarding the bacterial isolates identified during the samplings, 79 and 96 microorganisms were isolated in hospital A and B, respectively, in which 24.7 and $36.5 \%$ were Staphylococcus subsp.

The microorganisms prevalent in the evaluated sectors of Hospital A and B are shown in Figures 3 to 8.

In the ORT of hospital A (Figure 3), there was also the isolation in air of a lower percentage of Staphylococcus. hominis subsp. hominis (6\%) and Sphingomonas paucimobilis (6\%) (Data not shown).

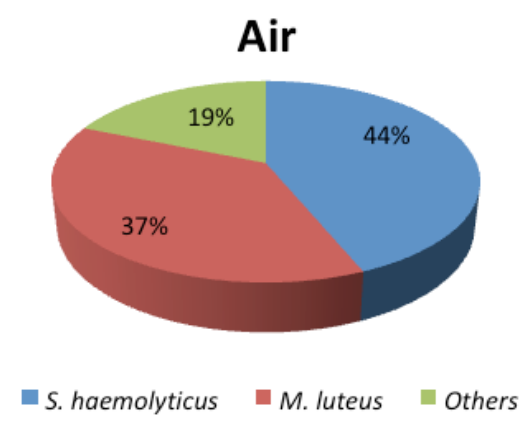

In the ICU air of hospital A (Figure 4), a lower percentage of Sphingomonas paucimobilis, Burkholderia gladioli, Staphylococcus hominis subsp. hominis, Staphylococcus warneri, Staphylococcus cohnii subsp. urealyticus, Staphylococcus lentus, Enterobacter ludwigii, and Kocuri. kristinae (all with $6 \%$, totalizing $48 \%$ ) were isolated; and in the surface were found Kocuria varians, Rhodococcus rhodochrous, Staphylococcus epidermidis, Staphylococcus saprophyticus, Paenibacillus polymyxa and Corynebacterium subsp. (all with 9\%, totalizing 54\%) (Data not shown).

FIGURE 3 - Microorganisms identified in air and surface samples of operating room theaters (ORT) - Hospital A.

\section{Air}
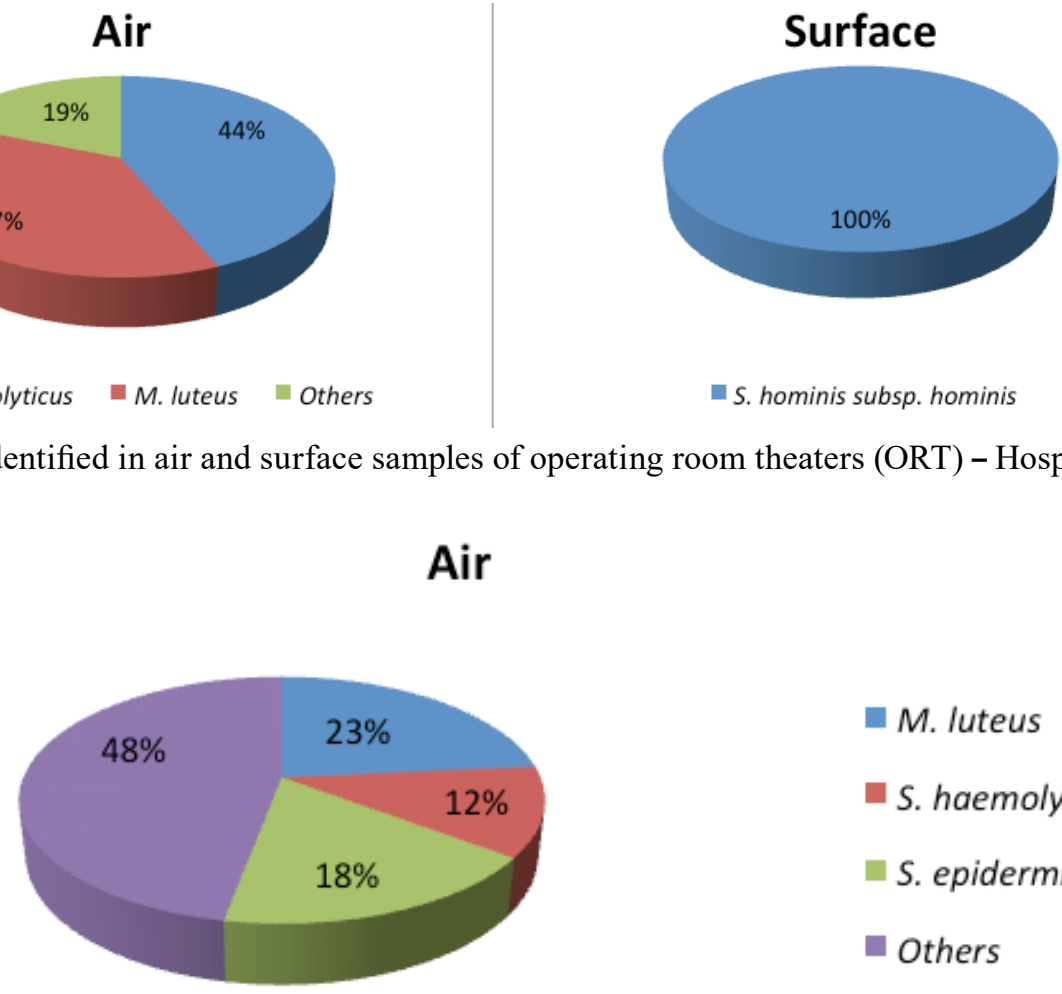

M. luteus

S. haemolyticus

S. epidermidis

others

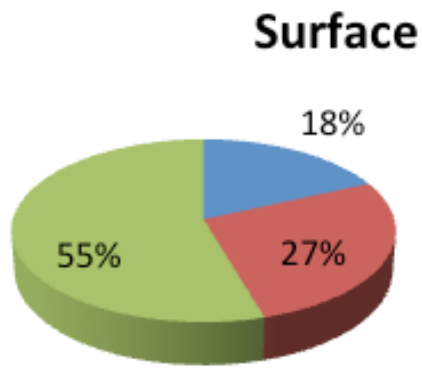

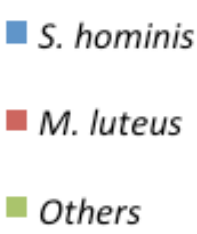

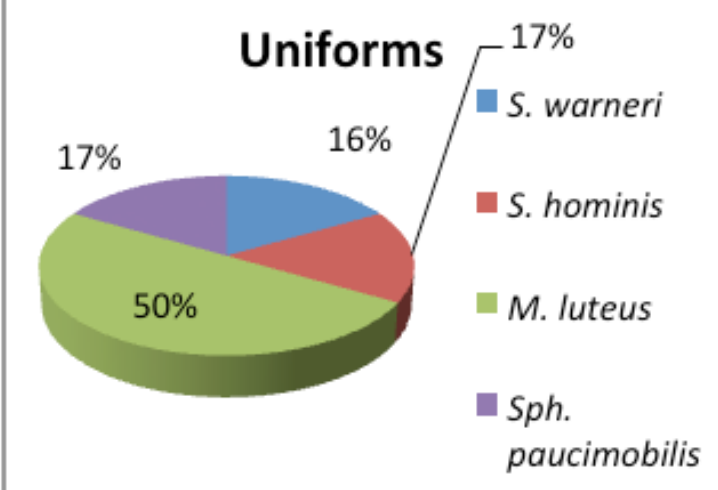

FIGURE 4 - Microorganisms identified in air, surface and uniforms samples of Intensive care unit (ICU) - Hospital A. 
In the MSC of hospital A (Figure 5), a lower percentage of the following microorganisms were found in the air: Micrococcus luteus, Staphylococcus saprophyticus (both with 10\%), Staphylococcus lentus, Staphylococcus capitis, Staphylococcus epidermidis, Staphylococcus cohnii spp cohnii, Staphylococcus cohnii spp urealyticus and Oligella ureolytica (all with 5\%, totalizing 30\%); in the surface were found $S$. hominis subsp. hominis (15\%), Sph. paucimobilis, E. ludwigii, Pasteurella canis and Bacillus simplex (all with 14\%, totalizing 56\%) (Data not shown).
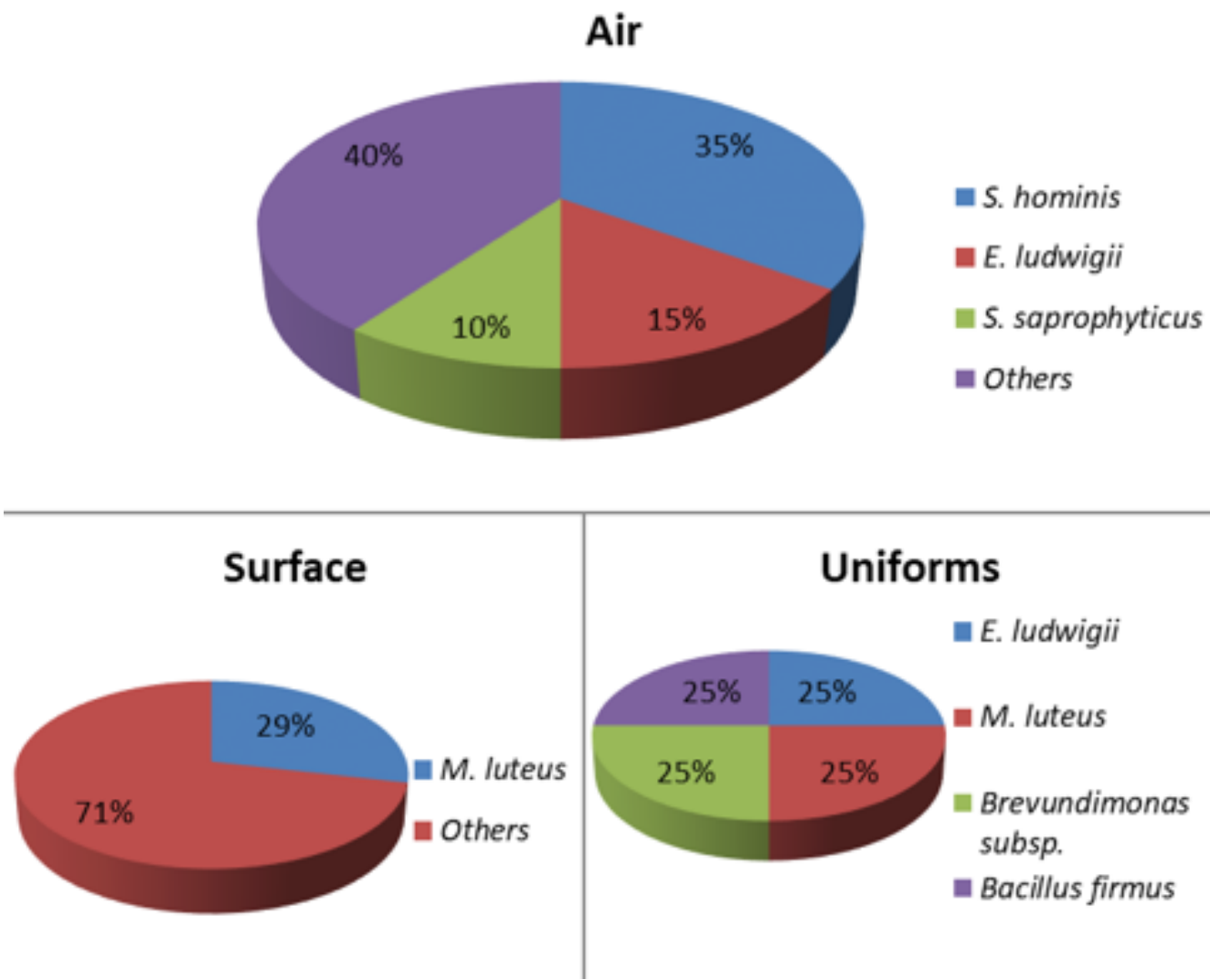

FIGURE 5 - Microorganisms identified in air, surface and uniforms samples of Material and sterilization center (MSC) - Hospital A.

In the ORT of hospital B (Figure 6), a lower percentage of the following were also isolated in air: $S$. epidermidis, $K$. rosea (both with 9\%), S. hominis subsp. hominis, S. cohnii subsp. urealyticus, S. warneri, $S$. capitis, Enterobacter ludwigii, Bacillus thuringiensis, Paenibacillus glucanolyticus (all with 5\%, totalizing $35 \%$ ) and S. lentus (4\%) (Data not shown).

In the PSRR of hospital B (Figure 7), there was also the isolation in air of a lower percentage of Bacillus cereus, S. epidermidis, Staphylococcus lugdunensis (all with $6 \%$, totalizing $18 \%$ ); and in surface were found
E. ludwigii, Bacillus amyloliquefaciens, $K$. varians, $K$. kristinae (all with 7\%, totalizing 28\%) and $S$. lugdunensis (6\%) (Data not shown).

In the MSC of hospital B (Figure 8) was found in the air a low percentage of Micrococcus lylae, Bacillus thuringiensis, S. epidermidis, Staphylococcus caprae and Staphylococcus sciuri (all with 5\%, totaling $25 \%$ ); in the surface were found $S$. saprophyticus, $S$. hominis subsp. hominis, $M$ lylae, $B$. thuringiensis and Ochrobactrum anthropic (all with 8\%, totalizing 40\%) (Data not shown). 

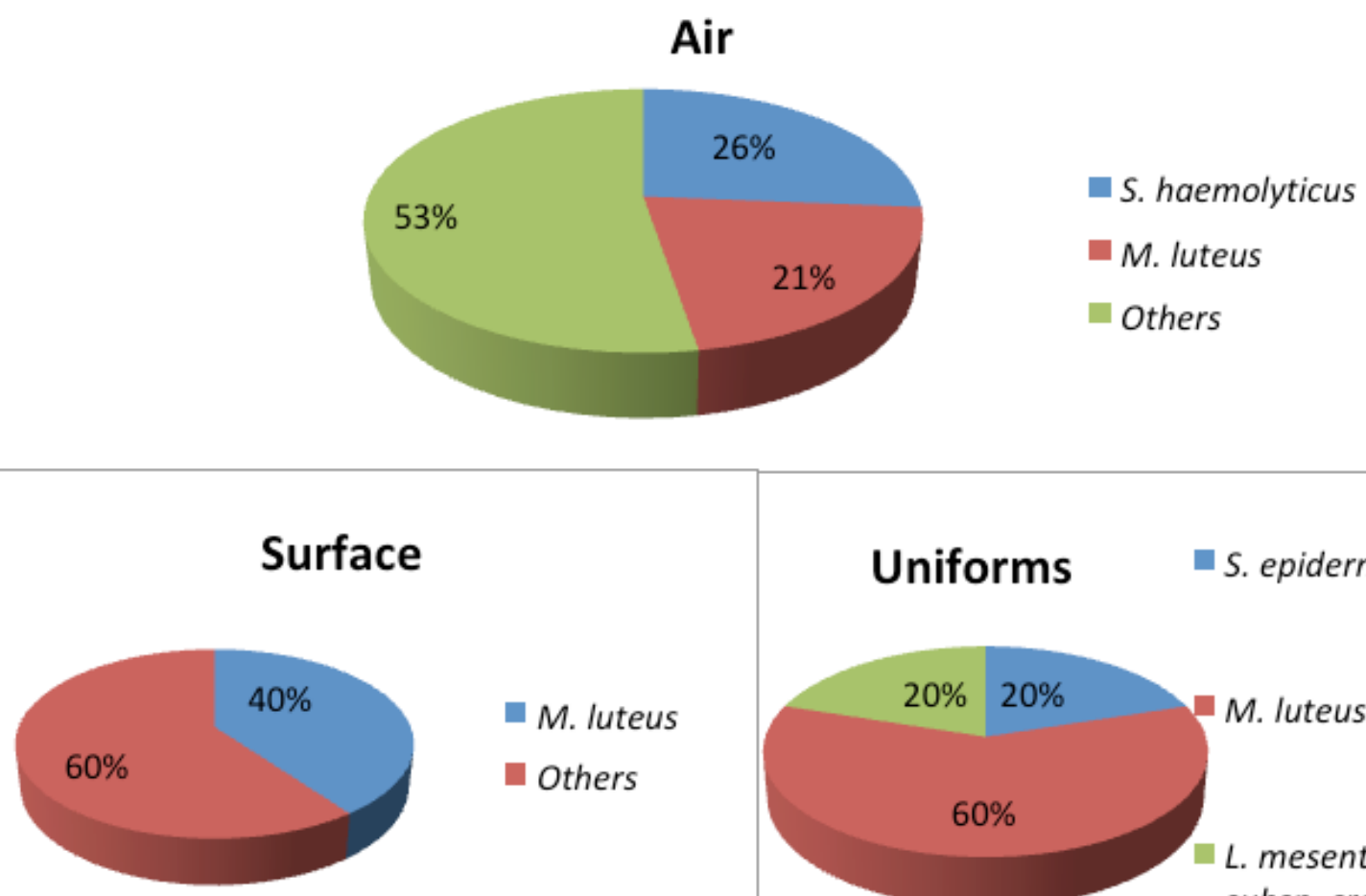

\section{Uniforms $\quad$ S. epidermidis}

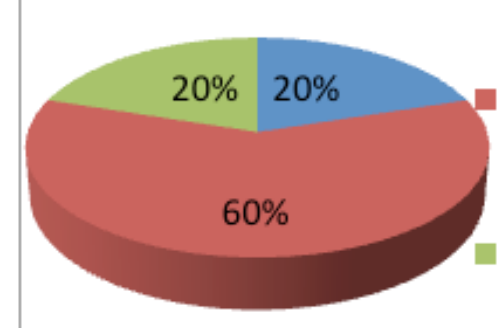

L. mesenteroides subsp. cremoris

FIGURE 6 - Microorganisms identified in air, surface and uniforms samples of operating room theaters (ORT) - Hospital B.

\section{Air}

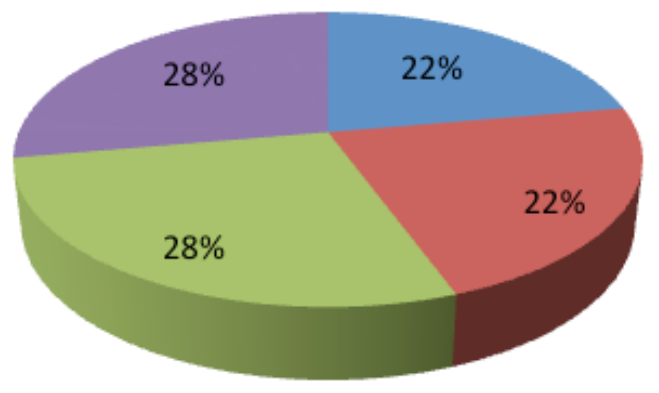

S. haemolyticus

S. hominis subsp. hominis

M. luteus

Others

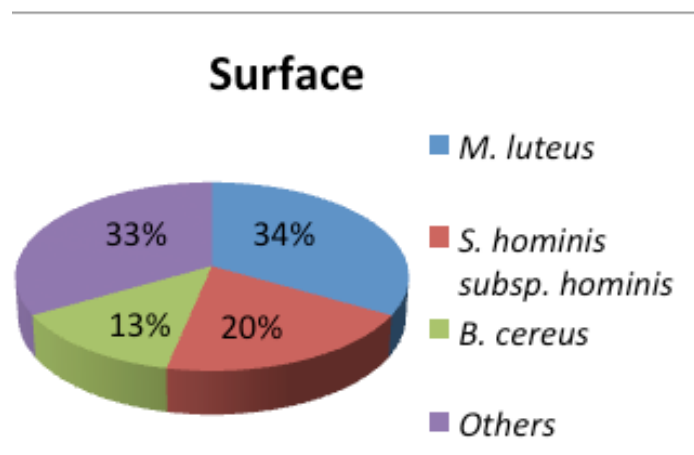

\section{Uniforms}

S. capitis

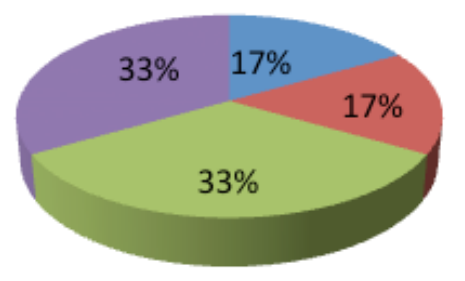

- Pantoea

subsp.

M. luteus

B. cereus

FIGURE 7 - Microorganisms identified in air, surface and uniforms samples of Post-surgical rest room (PSRR) - Hospital B. 

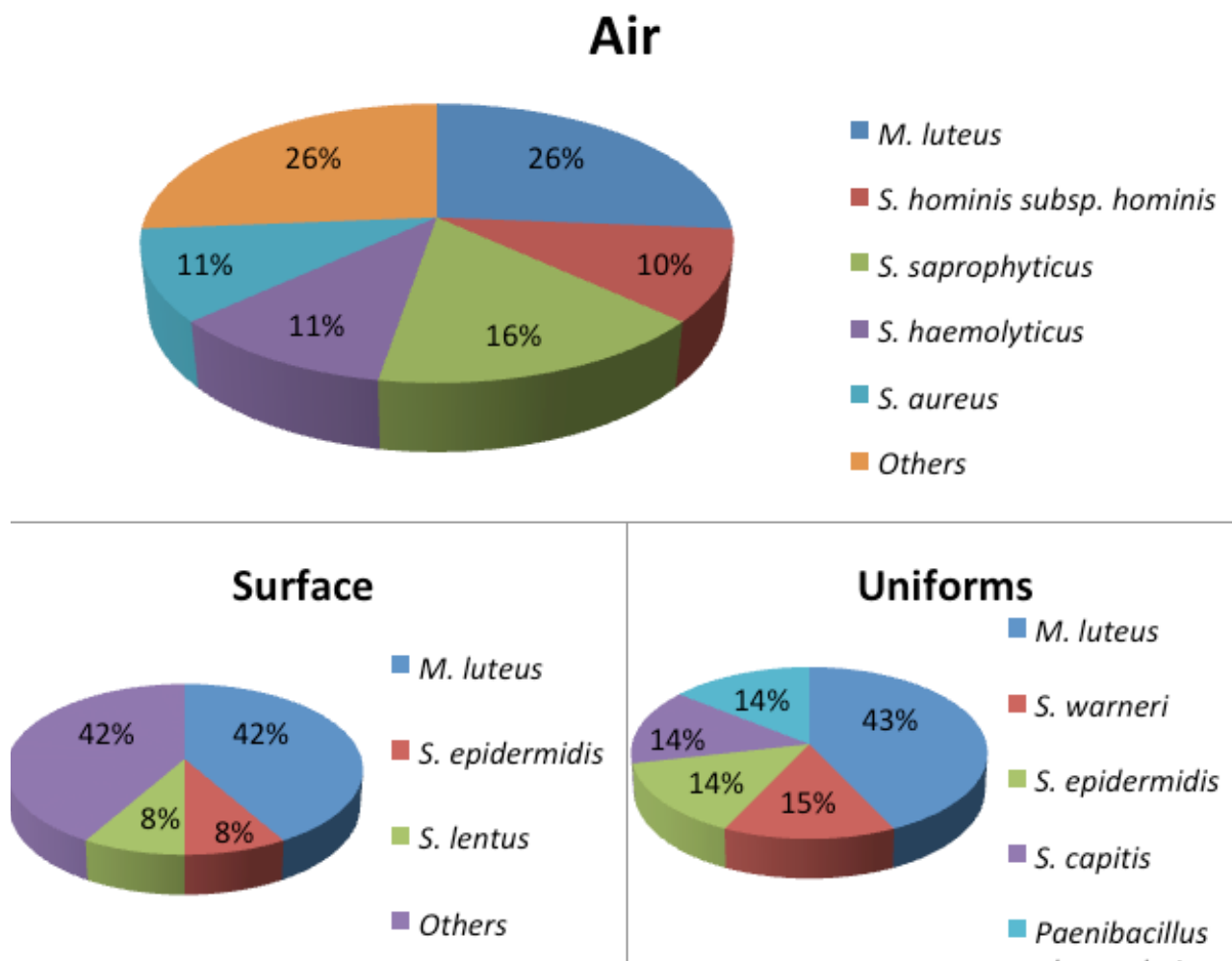

FIGURE 8 - Microorganisms identified in air, surface and uniforms samples of Material and sterilization center (MSC) - Hospital B.

\section{Antimicrobial susceptibility}

In general, more than $90 \%$ of the bacteria isolated from both hospitals were resistant to at least one of the evaluated antibiotics. Simultaneous resistance to azithromycin and penicillin (all isolates, as described in Table 1) was quite common, especially in bacteria isolated from the air.

In the analyzed hospitals, the bacteria (Staphylococcus subsp. and others Gram-positive cocci) were resistant to oxacillin, with $31.25 \%$ from hospital A and $34.8 \%$ from hospital $\mathrm{B}$, for which one and eight isolated were in the air of the surgical centers (Hospital A and B, respectively).

Extensively drug-resistant (XDR) bacteria (Table I) were detected in several environments evaluated in air, surface and uniform samples. The largest number of XRD strains were isolated in the MSC and ORT of hospital B, both presenting five XRD strains (35.7\%), followed by the ICU of hospital A with two XRD strains $(14.3 \%)$. In some samples the isolated analyzed were resistant to azithromycin, oxacillin, penicillin, clindamycin and vancomycin $(57,14 \%$ in all hospitals). 
TABLE I - Extensively drug-resistant bacteria isolated in the evaluated hospitals

\begin{tabular}{|c|c|c|c|}
\hline Strain & Antimicrobial resistance & Sensitivity & Area \\
\hline S. haemolyticus & Azi/Pen/Clin/Van/Cip & Oxa/Gen & ORT's air - H.A ${ }^{3}$ \\
\hline S. epidermidis & Azi/Oxa/Pen/Gen/Clin & Van/Cip & ICU's air - H.A ${ }^{3}$ \\
\hline S. hominis subsp. hominis & Azi/Oxa/Pen/Gen/Clin & Van/Cip & ICU's sup ${ }^{1}-$ H.A ${ }^{3}$ \\
\hline S. hominis subsp. hominis & Azi/Oxa/Pen/Gen/Clin & Van/Cip & MSC's air - H.A ${ }^{3}$ \\
\hline S. haemolyticus & Azi/Oxa/Pen/Gen/Clin & Van/Cip & ORT's air - H.B ${ }^{4}$ \\
\hline S. haemolyticus & Azi/Oxa/Pen/Clin/Van & Gen/Cip (i) & ORT's air - H.B ${ }^{4}$ \\
\hline M. luteus & Azi/Oxa/Pen/Clin/Van & Gen/Cip & ORT's air - H.B ${ }^{4}$ \\
\hline K. rosea & Azi/Oxa/Pen/Clin/Van & Gen/Cip & ORT's air - H.B ${ }^{4}$ \\
\hline $\begin{array}{l}\text { L. mesenteroides } \\
\text { subsp. cremoris }\end{array}$ & Azi/Oxa/Pen/Clin/Van & Gen/Cip (i) & ORT's unif ${ }^{2}-$ H.B ${ }^{4}$ \\
\hline S. hominis subsp. hominis & Azi/Oxa/Pen/Gen/Clin & Van/Cip & MSC's air - H.B ${ }^{4}$ \\
\hline M. luteus & Azi/Oxa/Pen/Clin/Van & Gen/Cip & MSC's air - H.B ${ }^{4}$ \\
\hline M. luteus & Azi/Oxa/Pen/Clin/Van & Gen/Cip & MSC's sup ${ }^{1}-$ H.B ${ }^{4}$ \\
\hline M. luteus & Azi/Oxa/Pen/Clin/Van & Gen/Cip & MSC's sup ${ }^{1}-$ H.B ${ }^{4}$ \\
\hline M. luteus & Azi/Oxa/Pen/Clin/Van & Gen/Cip & MSC's unif ${ }^{2}-\mathrm{H}^{\prime} \mathrm{B}^{4}$ \\
\hline
\end{tabular}

Azi: Azithromycin; Cip: Ciprofloxacin; Clin: Clindamycin; Gen: Gentamicin; Oxa: Oxacillin; Pen: Penicillin; Van: Vancomycin. (i): Intermediate. ${ }^{1}$ Surface; ${ }^{2}$ Uniform; ${ }^{3}$ Hospital A; ${ }^{4}$ Hospital B. ORT: operating room theater; ICU: intensive care unit; MSC: material and sterilization center.

\section{DISCUSSION}

The microbial load and the isolated microbiota in this study, the highest microbial load was found in the PSRR (566 CFU $/ \mathrm{m}^{3}$, Hospital B) and the lowest in the ORT (124.5 CFU $/ \mathrm{m}^{3}$, Hospital B), isolating predominantly Staphylococcus subsp. (26\% S. haemolyticus and 20\% S. epidermidis in general) and Micrococcus luteus (40\%).

There are several studies that have displayed similar results to this work (Cabo Verde et al., 2015; Tang et al., 2013; Wan et al., 2011). This is exemplified by a Portuguese study (Cabo Verde et al., 2015) that found a microbial load ranging from 12 to $170 \mathrm{CFU} / \mathrm{m}^{3}$ in ORT, 240 to
$736 \mathrm{CFU} / \mathrm{m}^{3}$ in ES (Emergency service) and 99 to 495 $\mathrm{CFU} / \mathrm{m}^{3}$ in SW (Surgical ward), isolating predominantly Staphylococcus subsp. (S. aureus, S. capitis, S. hominis, S. epidermidis and $S$. warneri) and Micrococcus (M. luteus and M. lylae).

The UK Department of Health Technical memorandum (HTM 03-01) (Department of Health/ Estates and Facilities Division, 2007) determines the ORT limits during activity of $180 \mathrm{CFU} / \mathrm{m}^{3}$. Based on this legislation only the ORT of hospital B presented high airborne microbial load, and for the other sites (ICU and MSC) there are no recommendations. One point that should be highlighted is that, although it is required 
according to hospital norms, the ORT of Hospital B does not present positive internal pressure higher than in adjacent rooms, a factor that contributes to the increase of aerial microbial load and, consequently, to the risk of infection.

The statistical difference $(\mathrm{p}<0.01)$ between active and passive sampling is probably due to active sampling being a quantitative method, its unit is expressed in $\mathrm{m}^{3}$ of air, as opposed to passive sampling, which is not a quantitative method, since it is not possible to determine the amount of air coming into contact with the exposed plate.

The evaluation of air quality, surfaces and uniforms is an important tool for the investigation and prevention of hospital infection outbreaks. Compared to other studies, which only identified the strains isolated from air samples, surfaces and uniform, this study determined the resistance profile of the isolated microorganisms. Several multidrugresistant microorganisms were found, mainly in the MSC and in the ORT (Hospital B) and in the ICU (Hospital A).

These results are alarming, since, considering the exception of the MSC, where only healthcare workers have access, in the other areas the patient is exposed and comes in contact with these potential pathogens.

These findings show that in addition to the importance of assessing the microbial load of surfaces or environments, it is necessary to identify microorganisms and know their resistance profile (Table I - S. haemolyticus in the air at the ORT), where the aerial microbial load is within the recommended maximum limit of $180 \mathrm{CFU} / \mathrm{m}^{3}$ (HTM 03-01), and it also showed that multidrug-resistant bacteria were found in the sampled microbiota.

The isolation of $S$. haemolyticus and $S$. epidermidis multi-drug resistant (Table I) is a big concern because, despite being a common bacterium of the human microbiota, studies have shown these bacteria as emerging pathogens in nosocomial infections mainly involving medical devices and the formation of biofilms (Pinheiro et al., 2016).

The same happens with $S$. hominis subsp. hominis that has been reported as a potential pathogen isolated in generalized infections (Voineagu et al., 2012).

The organism $M$. luteus, found in several sampled environments, has been described as the causative agent in endocarditis (Miltiadous, Elisaf, 2011) and central venous catheter infection (Oudiz et al., 2004).

Some microorganisms isolated in low percentages in this study are described in some cases of nosocomial infections, is the case of E. ludwigii reported as an agent causing an outbreak of bloodstream infection (FloresCarrero et al., 2016); Bacillus cereus causing bacteremia, infection of skin, bones and joints (Veysseyre et al., 2015); S. lugdunensis causing bacteremia (Pereira et al., 2011); S. warneri causing endocarditis (Arslan et al., 2011) and $S$. cohnii subsp. urealyticus causing bacteremia (Soldera et al., 2013).

Multidrug-resistant bacteria are a worldwide public health problem, and investigating possible sources of these microorganisms is very important to prevent outbreaks. According to the results of this study, multi-resistant bacteria can be present in places that present risk to both the patients and healthcare workers (MSC, ORT and ICU, Table I).

Regarding patients, the risk is imminent because the hospitalized patient has a weakened immune system, which determines a predisposition to suffering an infection when coming into contact with a potential pathogen (Cabrera-Cancio, 2012).

In the case of healthcare professionals, when they come into contact with these microorganisms through the air or on work surfaces and even in uniforms, these workers can become reservoirs that assist in the dissemination of these pathogens (Chemaly et al., 2014).

The differential of this study is the investigation of the resistance profile of isolated microorganisms, a fact that may pose risks to health professionals but especially to patients exposed to these types of microorganisms. From this investigation, previously neglected sites should be monitored so as not to become a source of spread of resistant pathogens.

\section{CONCLUSION}

A large number of multi-drug resistant microorganisms (14 strains) have been isolated from environments, even within the recommended microbial load limits, that pose risks to patients such as the operating theater (ORT) and intensive care unit (ICU).

The results show that environmental monitoring, using an active sampling method, is an important tool, and should be adopted by hospital infection control committees to investigate, control and reduce the occurrence of nosocomial infections, mainly from sources such as the air, surfaces and uniforms.

\section{CONFLICT OF INTEREST STATEMENT}

None declared. 


\section{ACKNOWLEDGEMENTS}

The authors are grateful to the directors and health professionals of the hospitals where this research was conducted. We would like to thank the FAPEG (Fundação de Amparo à Pesquisa do Estado de Goiás - Foundation for Research Support of the State of Goiás) for the financial support in this developed research.

\section{REFERENCES}

Agodi A, Auxilia F, Barchitta M, Cristina ML, D’Alessandro $\mathrm{D}$, Mura I, et al. Operating theatre ventilation systems and microbial air contamination in total joint replacement surgery: Results of the GISIO-ISChIA study. J Hosp Infect. 2015;90(3):213-9. doi:10.1016/j.jhin.2015.02.014.

Arslan F, Saltoglu N, Mete B, Mert A. Recurrent Staphylococcus warnerii prosthetic valve endocarditis: a case report and review. Ann Clin Microbiol Antimicrob. 2011;10:14. doi:10.1186/1476-0711-10-14.

Baughman A, Arens EA. Indoor Humidity and Human Health--Part I: Literature Review of Health Effects of Humidity-Influenced Indoor Pollutants. ASHRAE Trans. 1996;102 Part 1:193-211.

Birgand G, Toupet G, Rukly S, Antoniotti G, Deschamps MN, Lepelletier D, et al. Air contamination for predicting wound contamination in clean surgery: A large multicenter study. Am J Infect Control. 2015;43(5):516-21. doi:10.1016/j. ajic.2015.01.026.

Cabo Verde S, Almeida SM, Matos J, Guerreiro D, Meneses M, Faria T, et al. Microbiological assessment of indoor air quality at different hospital sites. Res Microbiol. 2015;166(7):557-63. doi:10.1016/j.resmic.2015.03.004.

Cabrera-Cancio MR. Infections and the Compromised Immune Status in the Chronically Critically Ill Patient: Prevention Strategies. Respir Care. 2012;57(6):979-92. doi:https://doi.org/10.4187/respcare.01621.

Chemaly RF, Simmons S, Dale C, Ghantoji SS, Rodriguez M, Gubb J, et al. The role of the healthcare environment in the spread of multidrug-resistant organisms: update on current best practices for containment. Ther Adv Infect Dis. 2014;2(23):79-90. doi:10.1177/2049936114543287.

CLSI. M100-S25 Performance Standards for Antimicrobial Susceptibility Testing; Twenty-Fifth Informational Supplement. 2015.
Cornejo-Juárez P, Vilar-Compte D, Pérez-Jiménez C, Ñamendys-Silva SA, Sandoval-Hernández S, VolkowFernández P. The impact of hospital-acquired infections with multidrug-resistant bacteria in an oncology intensive care unit. Int J Infect Dis. 2015;31:31-4. doi:10.1016/j.ijid.2014.12.022.

Creamer E, Shore AC, Deasy EC, Galvin S, Dolan A, Walley $\mathrm{N}$, et al. Air and surface contamination patterns of meticillin-resistant Staphylococcus aureus on eight acute hospital wards. J Hosp Infect. 2014;86(3):201-8. doi:10.1016/j. jhin.2013.12.005.

Dancer SJ. The role of environmental cleaning in the control of hospital-acquired infection. J Hosp Infect. 2009;73(4):37885. doi:10.1016/j.jhin.2009.03.030.

Department of Health/Estates and Facilities Division. Health Technical Memorandum 03-01: Specialised ventilation for healthcare premises. Part A - Design and installation. https://www.gov.uk/government/uploads/system/uploads/ attachment_data/file/144029/HTM_03-01_Part_A.pdf; 2007.

Emuren K, Ordinioha B. Microbiological assessment of indoor air quality at different sites of a tertiary hospital in South-South Nigeria. Port Harcourt Med J. 2016;10(2):79. doi:10.4103/0795-3038.189459.

Flores-Carrero A, Labrador I, Paniz-Mondolfi A, Peaper DR, Towle D, Araque M. Nosocomial outbreak of extendedspectrum $\beta$-lactamase-producing Enterobacter ludwigii coharbouring CTX-M-8, SHV-12 and TEM-15 in a neonatal intensive care unit in Venezuela. J Glob Antimicrob Resist. 2016;7:114-8. doi:10.1016/j.jgar.2016.08.006.

Galvin S, Dolan A, Cahill O, Daniels S, Humphreys H. Microbial monitoring of the hospital environment: why and how? J Hosp Infect. 2012;82(3):143-51. doi:10.1016/j. jhin.2012.06.015.

Kumari DNP, Haji TC, Keer V, Hawkey PM, Duncanson $\mathrm{V}$, Flower E. Ventilation grilles as a potential source of methicillin-resistant Staphylococcus aureus causing an outbreak in an orthopaedic ward at a district general hospital. J Hosp Infect. 1998;39(2):127-33. doi:10.1016/S01956701(98)90326-7.

Litvinov N, da Silva MTN, van der Heijden IM, Graça MG, Marques de Oliveira L, Fu L, et al. An outbreak of invasive fusariosis in a children's cancer hospital. Clin Microbiol Infect. 2015;21(3):268.el-268.e7. doi:10.1016/j.cmi.2014.09.004.

Miltiadous G, Elisaf M. Native valve endocarditis due to Micrococcus luteus: a case report and review of the literature. J Med Case Rep. 2011;5:251. doi:10.1186/1752-1947-5-251. 
Munoz-Price LS, Arheart KL, Mills JP, Cleary T, DePascale D, Jimenez A, et al. Associations between bacterial contamination of health care workers' hands and contamination of white coats and scrubs. Am J Infect Control. 2012;40(9):e245-8. doi:10.1016/j.ajic.2012.03.032.

Neidell MJ, Cohen B, Furuya Y, Hill J, Jeon CY, Glied S, et al. Costs of healthcare- and community-associated infections with antimicrobial-resistant versus antimicrobial-susceptible organisms. Clin Infect Dis. 2012;55(6):807-15. doi:10.1093/ cid/cis552.

Oudiz RJ, Widlitz A, Beckmann XJ, Camanga D, Alfie $\mathrm{J}$, Brundage $\mathrm{BH}$, et al. Micrococcus-associated central venous catheter infection in patients with pulmonary arterial hypertension. Chest. 2004;126(1):90-4. doi:10.1378/ chest.126.1.90.

Park DU, Yeom JK, Lee WJ, Lee KM. Assessment of the levels of airborne bacteria, gram-negative bacteria, and fungi in hospital lobbies. Int J Environ Res Public Health. 2013;10(2):541-55. doi:10.3390/ijerph10020541.

Pereira EM, Schuenck RP, Aranha Nouér S, Santos KRN dos. Methicillin-resistant Staphylococcus lugdunensis carrying SCCmec type V misidentified as MRSA. Brazilian J Infect Dis. 2011;15(3):293-5. doi:10.1016/S1413-8670(11)70192-1.

Pinheiro L, Brito CI, Oliveira A de, Pereira VC, Cunha M de LR de S da. Staphylococcus epidermidis and Staphylococcus haemolyticus: detection of biofilm genes and biofilm formation in blood culture isolates from patients in a Brazilian teaching hospital. Diagn Microbiol Infect Dis. 2016;86(1):114. doi:10.1016/j.diagmicrobio.2016.06.006.
Prussin AJ, Marr LC. Sources of airborne microorganisms in the built environment. Microbiome 2015;3:78. doi:10.1186/ s40168-015-0144-z.

Soldera J, Nedel WL, Cardoso PRC, D’Azevedo PA. Bacteremia due to Staphylococcus cohnii ssp. urealyticus caused by infected pressure ulcer: case report and review of the literature. Sao Paulo Med J. 2013;131(1):59-61.

Tang C-S, Wan G-H, Keer V, Hawkey P, Duncanson V. Air quality monitoring of the post-operative recovery room and locations surrounding operating theaters in a medical center in Taiwan. PLoS One. 2013;8(4):e61093. doi:10.1371/journal. pone.0061093.

Veysseyre F, Fourcade C, Lavigne J-P, Sotto A. Bacillus cereus infection: 57 case patients and a literature review. Médecine Mal Infect. 2015;45(11-12):436-40. doi:10.1016/j. medmal.2015.09.011.

Voineagu L, Braga V, Botnarciuc M, Barbu A, Tataru M. Emergence of staphylococcus hominis strains in general infections. ARS Medica Tomitana. 2012;18(2):80-2. doi:10.2478/v10307-012-0016-8.

Wan G-H, Chung F-F, Tang C-S. Long-term surveillance of air quality in medical center operating rooms. Am J Infect Control. 2011;39(4):302-8. doi:10.1016/j.ajic.2010.07.006.

Received for publication on $19^{\text {th }}$ November 2018 Accepted for publication on $19^{\text {th }}$ September 2019 